\title{
Rigour in the Management Case Study Method: A Study on Master's Dissertations
}

\author{
Miguel Varela, Paula Lopes and Rosa Rodrigues \\ Instituto Superior de Gestão, Lisboa, Portugal \\ miguelvarela@isg.pt \\ paulalopes@isg.pt \\ rosa.rodrigues@isg.pt
}

\begin{abstract}
Many authors argue that the case study is a valid and advantageous research method for certain studies, having been used as a method of academic research in the field of social sciences as well as in management. This research method is an integrated system and offers the opportunity for a holistic view that combines data collection methods such as archival searches, interviews, questionnaires and observation. The data collection needed to build a case study is labour-intensive, can last months or even years, and data overload seems almost inevitable. The case study is an empirical inquiry that investigates a contemporary phenomenon within a real-life context. In this research method, qualitative data usually predominates, but quantitative data often appears in case studies. Some research studies consider the case study to be a research method for validating and constructing theory. Other research highlights that all social science studies must start with a theory based on a review of the literature relating to the subject under investigation and this theory must then be validated through the study of a specific object, phenomenon or social problem. The key point is that before a theory can be validated, it must be constructed. In other words, a theory or theoretical framework first emerges not through a deductive process but through the inductive approach of studying an empirical case or object, and finally all theories are initially based on a case or object. This type of research has traditionally been considered soft, due to the inexistence of criteria that allow to evaluate its validity as a method to study a phenomenon in its real context. The present work is part of this theme and intends to contribute to diminish the perception about the lack of rigour associated with the case study. The present research focuses on the analysis of the methodological rigour of defended master's dissertations. In this context an investigation was undertaken of master's dissertations in the management area of a higher education management institution that use the case study as the research method. In order to achieve our goals, four hundred and forty-two master's dissertations defended in management scientific master's degrees in a Portuguese higher education institution which specializes in the area of economic and business sciences were analysed. The results of the qualitative research indicate that $40.0 \%$ of the dissertations focus on case studies. The results obtained lead us to conclude that in general the dissertations analysed present a high level of methodological rigour with respect to the object of study and a moderate level with respect to data analysis and results. The most critical aspects are the way data are collected, namely the use of multiple sources of evidence in less than half of the cases, which makes triangulation of data impossible.
\end{abstract}

Keywords: Case study method, Rigour in qualitative research, Management scientific research, Master's dissertations, Economic and business sciences, University in Portugal

\section{Introduction}

The aim of this study was to analyse the methodological rigour of master's dissertations that used the case study method in their research strategies, as there has been an increase in management areas (Caldwell, 2019). Despite the increase in the number of dissertations based on a case study, this type of research has traditionally been considered soft, due to the lack of criteria to assess its validity as a method that allows study of a phenomenon in its real context (Yin, 2014).

Within the scope of this study, the following research questions were asked:

Q1: Are the master's dissertations anchored in the case study rigorous from a methodological point of view?

Q2: Is there a relation between the phenomenon studied and the context in which it is inserted?

The present work intends to answer these research questions and contribute to reduce the perception regarding the lack of rigor associated with the case study.

Academic discussion regarding the case study as a research method is a current topic that has registered increasing interest on the part of researchers. The focus has been on its rigour in qualitative research globally (e.g., Heale and Twycross, 2015; Gustafsson, 2017; Harrison et al., 2017; Harley and Cornelissen, 2019; Hoorani, Nair and Gibbert, 2019; Rashid et al., 2019; Alam, 2020; Johnson, Adkins and Chauvin, 2020; Molina-Azorin and Fetters, 2020), as well as its application in different research fields in particular in management and in different Method: A Study on Master's Dissertations. The Electronic Journal of Business Research Methods, 19(1), pp. 113, available online at www.ejbrm.com 
areas of management (Ketchen, Craighead and Cheng, 2018; Goffin et al., 2019; Myers, 2019; Verleye, 2019; Gephart and Saylors, 2020; Harrison, Reilly and Creswell, 2020; Shufutinsky, 2020).

This academic discussion started some years ago and continues in the present, increasing the number of studies on this theme that incorporate the case study method in different areas of management as a valid methodology to be applied in research studies with certain characteristics or as part of studies with various research methodologies (Harrison et al., 2017; Yin, 2017; Ketchen, Craighead and Cheng, 2018; Goffin et al., 2019; Gephart and Saylors, 2020; Holmlund, Witell and Gibbert, 2020).

In this sense, four hundred and forty-two master's dissertations defended in management scientific master's degrees in a Portuguese higher education institution which specializes in the area of economic and business sciences were analysed. After the first analysis, the results show that $40 \%$ of the total of the dissertations (442) focus on case studies, which proves their predominance in the research area of management.

After this introduction, this research work presents a literature review that includes the main studies related to the theme under study. An explanation of the methodology applied in this study then follows, with subsequent analysis of the results. After this, the discussion of the findings is presented, followed by the conclusion and finally the bibliographic references.

\section{Literature review}

\subsection{Case study method definition and advantages}

It is important to start with the definition of a case study. Gustafsson (2017) compile various definitions. A case study can be an intensive study about a person, a group of people or a unit, which is aimed to generalize over several units. In a case study, the focus is based on a specific unit.

Thomas (2011) states that a case study is an analysis of systems that are studied with a comprehensive view by either one or several methods. On the other hand, Cesar, Antunes and Vidal (2010) explain that the aim of a case study method is not to analyse cases, but it is a good way to define cases and to explore a setting in order to understand it. Cresswell (2013) consider that it explores a real-life, contemporary bounded system (a case) or multiple bounded systems (cases) over time, through detailed, in-depth data collection involving multiple sources of information.

Other authors consider that the case study research method is an integrated system and combines archival searches, interviews, questionnaires, and observation (Gehman et al., 2018). This vision is shared by Gephart and Saylors (2020), who define it as a method which provides a history of an event or phenomenon over time using multiple data sources and helps to answer questions out of control from researcher related with the phenomenon studied. The case study contributes to a better understanding of the individual phenomena, and the organizational and political processes of society (Piekkari and Welch, 2011; Harrison et al., 2017). It is a tool which is used to understand the form and reasons that led to a given decision. This research method is used to validate a theory, through the study of a specific object, phenomenon or social problem (Yin, 2017).

Alam (2020) highlights a feature of case studies which allow "what" questions along with "why" and "how" to be answered. Therefore, the formation of research questions which ask "what" should be for exploring comprehensive responses. Yin (2013) stated that this method is a better option when "how" or "why" questions are to be answered, if the researcher has little control over events and the focus is on a current phenomenon in a real-life context.

Rahman (2017) studies the advantages and disadvantages of using qualitative and quantitative approaches and methods. Among the main advantages of qualitative research, the author states that it: (i) produces a detailed description of participants' feelings, opinions, and experiences and interprets the meanings of their actions; (ii) interprets the human experience holistically and understands it in specific settings, because being an interdisciplinary field it covers a wide range of epistemological viewpoints, research methods and interpretive techniques for understanding human experiences; (iii) allows the study of individual cases or events; (iv) enables researchers to discover the participants' experience; (v) includes methods such as participant observation, unstructured interviews, and direct observation, describing records that are most commonly used for collecting data; (vi) has a flexible structure that can be constructed and reconstructed. The handicap highlighted is that it 
focuses on meanings and experiences and on the participants' experience rather than any other imperative issues in the context.

The data collection needed to build a case study is labour-intensive, can last months or even years, and data overload seems almost inevitable (Miles, Huberman and Saldana, 2014). In this research method, qualitative data usually predominates, but quantitative data often appears in case studies. Other authors consider the case study a research method to validate and construct theory. Rashid et al. (2019) highlights that all social science studies must start off with a theory based on a review of the literature relating to the subject under investigation and this theory must then be validated through the study of a specific object, phenomenon or social problem. The key point is that before a theory can be validated, it must be constructed. In other words, a theory or theoretical framework first emerges through the inductive approach of studying an empirical case or object, not through a deductive process.

We finish this overview with the definition of Yin (2017), one of the best known authors in this research field, according to which a case study is an empirical inquiry that investigates a contemporary phenomenon within a real-life context. For this author, the case study is the opportunity to shed empirical light on some theoretical concepts or principles. His studies highlights the use of a case study when the main research questions are "how" or "why" questions, when the author has little or no control over behavioural events, and the focus of the study is a contemporary phenomenon. Additionally, the author declares that the case study method has variations including single or multiple cases, can be limited to quantitative evidence or can be part of a mixed-methods study. He also defines three types of case studies used for research purposes: explanatory case studies, descriptive case studies and exploratory case studies (Yin, 2013; 2017).

According to Yin (2014), the researches that use the case study also present some weaknesses, namely when it is intended to make comparisons or predictions over time. In this context, it states that to maintain methodological rigor it is necessary to take into account six main sources of evidence: (i) documentation, (ii) archival records, (iii) interviews, (iv) direct observations, (v) participant observation and (vi) physical artifacts. Should also keep in mind that each of these sources has its strengths and weaknesses. In addition to the sources of evidence, the author defends the need for a database of case studies (e.g., reports of final case studies) and an evidence chain (e.g., the connection between the questions asked, the data collected and the final conclusions), because only through the triangulation of information collected through the various elements is it possible to guarantee methodological rigor (Yazan, 2015).

\subsection{The case study method in the management field}

Research in the management field has been changing in recent years and new approaches are constantly being developed. As new concepts appear, exploratory research which takes a theory-building perspective is needed and the case study is highly appropriate and has been considered the most commonly used. In several disciplines, the need for higher quality case study research has been recognized (Goffin et al., 2019).

Gephart and Saylors (2020) reveal that case study research is used and studied in different management areas such as operations management (Barratt, Choi and Li, 2011), industrial marketing (Piekkari and Welch, 2011) information systems (Johnson, Adkins and Chauvin, 2020) and finally supply chain management (Flynn, 2008).

Goffin et al. (2019) present the Case Study Evaluation Template (CASET), which can be used to assess the quality of the case study research and includes four categories: research design, data collection, data analysis and posthoc reflection on rigour. The final criterion in CASET was to ascertain if the authors of a case study had reflected on the rigour of their research, like measures to ensure validity and reliability (study replication).

\subsection{Rigour in Case Study}

The importance of rigour in case study methods is highlighted by several authors such as Miles, Huberman and Saldana (2014) and Yin (2014) and researchers agree on the importance of the use of different methodologies to increase knowledge (Gehman et al., 2018) and that the use of this methodology to build theory has been maturing in management research (Gephart and Saylors, 2020).

The rigour associated with the case study method is a topic that has been studied and that has appeared frequently in the literature review related to the management area (Johnson, Adkins and Chauvin, 2020). 
Consequently, it seems pertinent to list some authors who have published studies on this angle, as shown in Table 1.

Table 1: Rigour in the case study in the management field

\begin{tabular}{|c|c|}
\hline Authors & Key Ideas \\
\hline Gehman et al. (2018) & $\begin{array}{l}\text { In this study the authors compare three qualitative approaches to theory } \\
\text { building. We highlight here the overview of Katy Eisenhardt (Eisenhardt and } \\
\text { Graebner, 2007), which mentions the importance of the case study to build } \\
\text { new theory that is testable, generalizable, logically coherent and empirically } \\
\text { valid. It is particularly useful for answering "how" questions, may be either } \\
\text { normative or descriptive, and either process (i.e., focused on similarity) or } \\
\text { variance based. Theory building from cases is appropriate in several different } \\
\text { research situations and sometimes the goal is to elaborate on an existing } \\
\text { theory. }\end{array}$ \\
\hline Goffin et al. (2019) & The case study method is highly appropriate for innovation management. \\
\hline Harley and Cornelissen (2019) & $\begin{array}{l}\text { The authors conceptualize how rigour, as an essential quality of reasoning, } \\
\text { may be defined and qualify alternative methodological criteria for how the } \\
\text { rigour of any particular piece of research might be assessed. }\end{array}$ \\
\hline Rashid et al. (2019) & $\begin{array}{l}\text { Qualitative case study methodology enables researchers to conduct an in- } \\
\text { depth exploration of intricate phenomena within some specific context. This } \\
\text { article presents a checklist comprised of four phases: foundation phase, pre- } \\
\text { field phase, field phase, and reporting phase. }\end{array}$ \\
\hline Takahashi and Araujo (2019) & $\begin{array}{l}\text { The case study approach has been widely used in management studies and } \\
\text { the social sciences more generally. This paper aims to discuss opening up } \\
\text { research opportunities in case study research, its various applications, as well } \\
\text { as the criteria for rigour and validity. }\end{array}$ \\
\hline Verleye (2019) & $\begin{array}{l}\text { Designing, writing-up and reviewing case study research. "the multitude of } \\
\text { paths to rigorous research - in service research based upon a case study } \\
\text { approach. } \\
\text { This article offers a framework for reviewing case study research in terms of } \\
\text { rigour and creativity" }\end{array}$ \\
\hline Walker and Baxter (2019) & $\begin{array}{l}\text { Compares citation practices in case study research in accounting and } \\
\text { management with a focus on citations of Robert Yin. The results build on } \\
\text { previous studies that analyse how scholars apply case study methodology, } \\
\text { encouraging researchers to adopt greater transparency. }\end{array}$ \\
\hline Harrison, Reilly and Creswell (2020) & $\begin{array}{l}\text { Contributes with a mixed methods framework in order to contribute to rigour } \\
\text { as an interdisciplinary baseline for quality evaluation. }\end{array}$ \\
\hline Johnson, Adkins and Chauvin (2020) & $\begin{array}{l}\text { The authors highlight the quality indicators and attributes of rigour, as well as } \\
\text { the best practices in qualitative research design. }\end{array}$ \\
\hline Molina-Azorin and Fetters (2020) & $\begin{array}{l}\text { Describes how mixed methods and case study research approaches can be } \\
\text { applied together to enhance case descriptions and interpretations. }\end{array}$ \\
\hline Shufutinsky (2020) & $\begin{array}{l}\text { Study about transparency and rigour in qualitative organizational research } \\
\text { methods, that that can be used in qualitative inquiry in order to increase } \\
\text { transparency, rigour, credibility and trustworthiness of the research processes. }\end{array}$ \\
\hline
\end{tabular}

Author's elaboration (2020)

In the present study, the authors investigated the rigour of master's dissertations that used the case study as an investigation method of a management university.

In this case, the data was analysed according to the postulate of Marques, Camacho and Alcantara (2015) to assess the methodological rigour of investigations anchored in a case study. Additionally, the following parameters were evaluated: understanding of the real context phenomena and the existence of a relation between the studied phenomenon and the real context according to Yin (2017). Other parameters from different authors were studied: a description of the strategy used to explore and test the theories (Cesar, Antunes and Vidal, 2010); the research question typology (Godoy, 2006); the case study type (Harrison et al., 2017); the representativeness of the objective of the work (Stewart, 2014); the data collection sources (Ajayi, 2017); the existence of data triangulation (Heale and Forbes, 2013); an explanation of the procedures (Bhakar and Sikarwar, 2014); analysis of psychometric indicators (Hair et al., 2018); an explanation of the analyses performed (Heale and Twycross, 2015); a comparison with previous studies (Labani, Wadhwa and Asthana, 2017); and suggestions 
for future studies (Inayatullah, 2013). Below are more details of the study carried out and the results obtained. Table 2 summarizes the main authors and concepts studied.

Table 2: Categories for the analysis of methodological rigor and respective authors

\begin{tabular}{|l|l|}
\hline Categories & Authors \\
\hline Study object & $\begin{array}{l}\text { Godoy (2006); Cesar, Antunes and Vidal (2010); Yin (2017), Caldwell } \\
\text { (2019); Hoorani, Nair and Gibbert (2019) }\end{array}$ \\
\hline Data collection & $\begin{array}{l}\text { Cesar, Antunes and Vidal (2010); Yin (2010); Ajayi, (2017); Hoorani, Nari } \\
\text { and Gibbert (2019); Alam (2020) }\end{array}$ \\
\hline Data Analysis & Godoy (2006); Hair et al. (2018) \\
\hline Results & Cesar, Antunes and Vidal (2010); Labani, Wadhwa and Asthana (2017) \\
\hline
\end{tabular}

Adapted from Marques, Camacho and Alcantara (2015)

\section{Methodology}

The methodological procedure used in the present investigation is anchored in the mixed paradigm. With qualitative analysis it was possible to contextualize and collect information about the object of the study, the data collection, its analysis and respective results (Bogdan and Biklen, 2013); these data were subsequently coded and analysed quantitatively. The present work focuses on the analysis of master's dissertations defended in a Portuguese higher education institution which specializes in the area of economic and business sciences, in the post-Bologna period (between 2007 and 2019): a total of 442 defended dissertations. After the first analysis, it was found that $40.0 \%$ of the dissertations focus on a case study, which proves their predominance in the area of management (Figure 1 ). In this institution, the number of master's students $\left(2^{\text {nd }}\right.$ cycle) was 1000 , which represented about $30 \%$ of the total students who attended this institution in the period under analysis, with the remaining $70 \%$ being $1^{\text {st }}$ cycle students.

Afterwards, a detailed analysis of the theses defended in the last five years ( $n=100)$ was carried out, and it can be stated that $15.0 \%$ of them concern the trade/retail sector, followed by the manufacturing sector (13.0\%) and small and medium-sized enterprises (SMEs; 10.0\%).

It was also possible to ascertain that the average of the dissertations defended varies between 12 and $18(\mathrm{M}=$ 15.66 ; $S D=1.38)$, with the public management course presenting the highest values $(M=17.20 ; S D=0.83)$, followed by the master's in human potential management $(M=16.90 ; S D=1.28)$ and the master's in transport and logistics management $(M=16.33 ; S D=0.57)$.

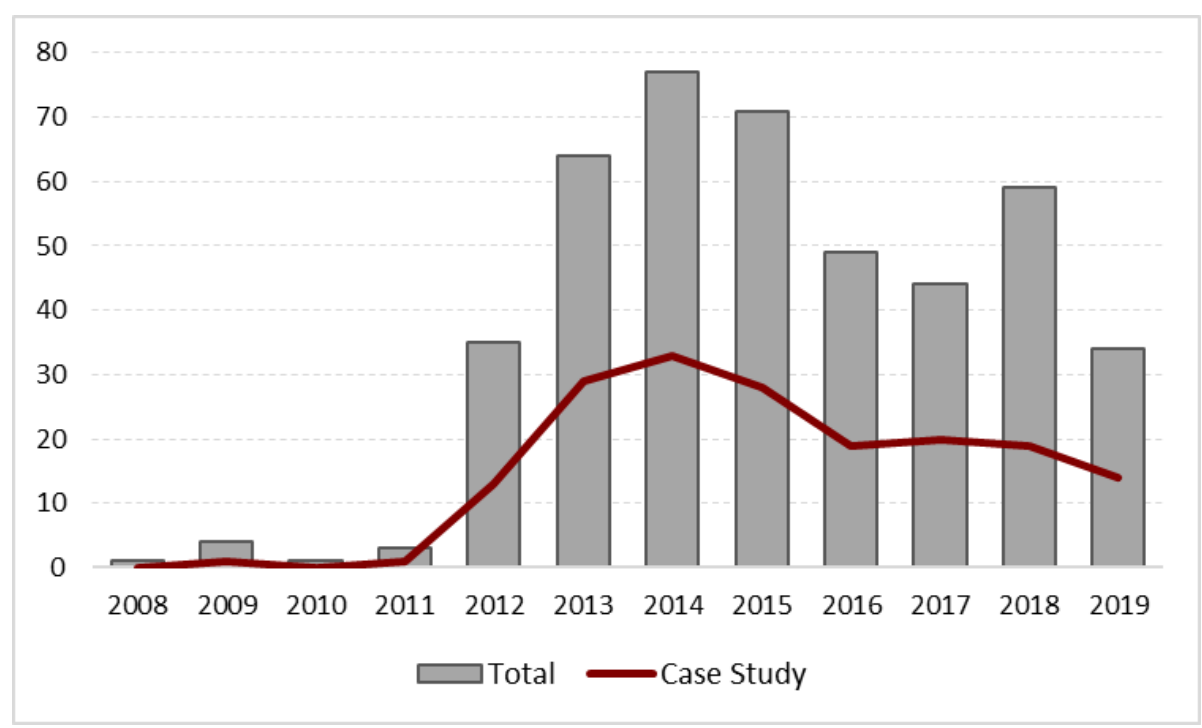

Figure 1: Evolution of master's dissertations defended between 2008 and 2019

The data was analysed according to the postulate of Marques, Camacho and Alcantara (2015) to assess the methodological rigour of the investigations that are anchored in the case study. Thus, the following parameters are evaluated:

1. Understanding of the real context of the phenomenon (Yin, 2017); 
2. Existence of a relation between the studied phenomenon and the real context (Yin, 2014);

3. Description of the strategy used to explore and test the theories (Cesar, Antunes and Vidal, 2010);

4. Research question typology (Godoy, 2006);

5. Case study type (Harrison et al., 2017);

6. Representativeness of the objective of the work (Stewart, 2014);

7. Data collection sources (Ajayi, 2017);

8. Existence of data triangulation (Heale and Forbes, 2013);

9. Explanation of the procedures (Bhakar and Sikarwar, 2014);

10. Analysis of psychometric indicators (Hair et al., 2018);

11. Explanation of the analyses performed (Heale and Twycross, 2015);

12. Comparison with previous studies (Labani, Wadhwa and Asthana, 2017);

13. Suggestions for future studies (Inayatullah, 2013).

After analysing the content of the dissertations, the variables were recoded, with one (1) being assigned to the presence of the referred criteria and zero (0) to their absence.

The data were grouped into four dimensions (Marques, Camacho and Alcantara, 2015) in order to facilitate the reading, with the aim of assessing the methodological rigour of the analysed dissertations, regarding:

1. The object of study (criteria 1 to 6 );

2. Data collection (criteria 7 to 9 );

3. Data analysis (criteria 10 and 11);

4. Results (criteria 12 and 13).

\section{Results}

In the first phase, the dissertations anchored in the case study were analysed from a qualitative point of view in order to identify the criteria referred to in the methodology. The data resulting from this first analysis were coded and analysed quantitatively, with the results being presented in the order of the criteria recommended by Marques, Camacho and Alcantara (2015).

The quantitative analysis of the data obtained from the qualitative study revealed that all the dissertations analysed $(n=100)$ seek to understand the phenomenon studied in its real context (criterion 1$)$ and that there is a connection between this phenomenon and the context in which it is inserted (criterion 2). It was also possible to verify that $45.0 \%$ of the dissertations explain the strategy used to explore and test the theories related to the object of study and the need to proceed with the case study to investigate the proposed phenomenon, which would not be possible with other strategies (criterion 3).

The results mentioned are evident in the excerpts that are transcribed below:

"The present dissertation resulted from a research work carried out in a logistics and express delivery company, which was operationalized through a case study. This methodology allowed us to evaluate how the company's image influences the opinion of its external public, because only by collecting the data in a real context is it possible to intervene in a context that is not clearly defined" (Dissertation No. 14).

"In methodological terms, we opted for a case study, in order to understand how, with regard to leadership styles, theory combines with practice of the supervisors of the organization under study" (Dissertation No. 68).

The fourth criterion sought to ascertain the typology of the research question and it was found that questions starting with "how" appeared in 79 dissertations, followed by questions of the "what" type with 14.0\%, those that start with "why" with $3.0 \%$, and $4.0 \%$ which have no questions.

These results can be corroborated in the following excerpts:

"How do employer branding strategies influence the company's internal and external environment?"

(Dissertation No. 34).

"How can logistics affect the company's competitiveness?" (Dissertation No. 13). 
When analysing the type of study (criterion 5), we found that $51.0 \%$ of the dissertations fall into the descriptive type, $34.0 \%$ in the exploratory type and $15.0 \%$ in the experimental type (cause-effect).

These values can be confirmed in the following segments:

"This is an exploratory and descriptive study, so it is not intended to generalize any conclusions to a more comprehensive group, in addition to the organization itself, and the results found may serve as a reflection or as a starting point for intervention in other organizations" (Dissertation No. 46).

"This investigation is part of a descriptive typology, since the data are collected by analysing reports, balance sheets, balance sheets and internal publications of the organization, from which an analysis of the frequencies of the variables under study was made" (Dissertation No. 86).

By means of the sixth criterion it was possible to ascertain that the study is representative for the purpose of the investigation in $29.0 \%$ of the dissertations analysed, with $91.0 \%$ justifying the choice of a single case and $9.0 \%$ for choosing multiple cases, as can be seen in the following fragment:

"The educational establishment chosen has a total of 201 students, spread over 10 classes. Nine children whose parents did not authorize participation in the study and one child with Asperger's disorder were excluded. Thus, 191 students participated in the present investigation, which is equivalent to a response rate of 95.0\%. This allowed us to guarantee the representativeness of the sample for the subject under study" (Dissertation No. 3).

The analysis of the criteria related to data collection (criterion 7), revealed that the data were collected from various sources in $40.0 \%$ of the dissertations, with documentary analysis standing out in relation to the rest $(65.0 \%)$, followed by interviews $(45.0 \%)$ and finally questionnaires $(37.0 \%)$. It was also possible to ascertain that there was triangulation of data in $22.0 \%$ of the cases (criterion 8 ), as can be seen in the passage below:

"The methodological procedure seeks to give work, rigour, objectivity and reliability, so quantitative and qualitative techniques will be applied. We tried not to condition data collection to a single method to reduce the bias of the results and subjectivity in the interpretation of the results, as well as to collect a set of information that would better answer the questions presented in this study. In this context, a questionnaire survey will be used due to its precise and formal nature of construction and practical application; and semi-structured interviews that allow the collection of richer, more in-depth and detailed information" (Dissertation No. 18).

Regarding the procedures (criterion 9), the results show that they were accurately explained in $99.0 \%$ of the dissertations, as can be seen from the following example:

"First, a vast literature review was carried out on the subject under study and from which the questions contained in the interview guide were outlined. The information was collected individually in a space suitable for that purpose, at the premises of the participating companies. All interviews were recorded and, once again, it was stressed that the data collected is intended for academic purposes only and that it will not be disclosed to third parties. After data collection, the interviews were transcribed in full, so that they could be treated. Subsequently, content analysis was performed, following the steps recommended in the literature, namely: (i) pre-analysis; (ii) exploration of the material; (iii) treatment of results, inference and interpretation" (Dissertation No. 36).

The tenth and eleventh criteria are dedicated to data analysis, and it was found that $82.0 \%$ of the dissertations used a qualitative approach, $38.0 \%$ opted for a quantitative approach and $20.0 \%$ used a mixed methodology. These results can be seen in the following texts:

"In this work, we chose to follow a qualitative content analysis, based on the five steps suggested by Bardin (2011): (i) transcription of the interviews; (ii) reflected reading and analysis; (iii) identification and description of the information units mentioned by the participants (initial coding); (iv) inductive analysis of the identified units and their grouping (axial coding)" (Dissertation No. 58).

"The data were analysed using a mixed methodology, as we believe that the combination of quantitative and qualitative techniques makes the research stronger and reduces the bias of the results" (Dissertation No. 61). 
It is important to mention that in a universe of 38 dissertations in which data were analysed quantitatively, only 21.1\% $(n=8)$ study the psychometric properties of the instruments used in order to guarantee their level of scientific and the robustness of the constructs evaluated by them. It was also possible to ascertain that the explanation about the analyses carried out is present in $74.0 \%$ of the dissertations. The passages presented allow these results to be validated.

"First, an exploratory factor analysis was carried out using the main component methodology and the psychometric properties of the resulting factors were analysed in order to guarantee the robustness and reliability of the scale" (Dissertation No. 65).

"The analysis of internal consistency was performed using Cronbach's alpha coefficient, which revealed that all dimensions of the questionnaire have values greater than 0.75 . This suggests that, from the point of view of fidelity, the questionnaire proves to be quite adequate" (Dissertation No. 99).

The last two criteria focus on the results, namely the comparison of the data obtained with previous studies and the attention to points that still need to be continued in terms of research. In this context, it was found that $65.0 \%$ of the dissertations do not consider what has already been done on the investigated topic, as they do not compare their findings with previously published studies (criterion 12). On the other hand, $81.0 \%$ of the cases presented suggestions for future work, which can be explained by the fact that most studies are descriptive or exploratory and do not explain the cause-effect relationships between the variables analysed (criterion 13). These conclusions are confirmed by the following text segments:

"In the particular case of this study, it is recommended to include instruments that allow the motivation and professional satisfaction of employees to be assessed in order to ascertain whether the organizational commitment is influenced by these variables" (Dissertation No. 1).

"It is suggested that future studies also consider the possibility of collecting data that allows the subjective and objective organizational performance to be measured, using economic and financial information. This variable could give us information about the real return on investment in a time frame to be defined. It would also be pertinent to carry out longitudinal studies that would allow analysis of the relationship between the variables under study, over time" (Dissertation No. 54).

Additionally, the level of methodological rigour of the dissertations analysed was studied. For this purpose, the 13 criteria were grouped into the four dimensions postulated by Marques, Camacho and Alcantara (2015): (i) object of study; (ii) data collection; (iii) data analysis; (iv) results. As previously mentioned, all criteria were evaluated on a dichotomous scale $(0=$ absence of the criterion and $1=$ presence of the criterion), the score being calculated by adding all the requirements found for each dimension. The maximum score depends on the number of requirements that composes each dimensions.

To evaluate the level of methodological rigour of the assessed dissertations, the results obtained were divided into quartiles, with the following classification being attributed: (i) low level methodological rigour (LMR), (ii) moderate level methodological rigour (MMR), (iii) high level methodological rigour (HMR) and (iv) very high level methodological rigour (VHMR) obtaining the results shown in Table 3.

Table 3: Methodological rigor of the dissertations analysed

\begin{tabular}{|l|c|c|c|c|}
\hline & LLMR & MLMR & HLMR & VHLRM \\
\hline Study object & $4.0 \%$ & $37.0 \%$ & $43.0 \%$ & $16.0 \%$ \\
\hline Data collection & $59.0 \%$ & $21.0 \%$ & $15.0 \%$ & $5.0 \%$ \\
\hline Data analysis & $25.0 \%$ & $66.0 \%$ & $7.0 \%$ & $2.0 \%$ \\
\hline Results & $19.0 \%$ & $46.0 \%$ & $31.0 \%$ & $4.0 \%$ \\
\hline
\end{tabular}

Author's elaboration

The results suggest that the dissertations defended in the analysed higher education institution, between 2015 and 2019 , in terms of the object of study present $4.0 \%$ of LLMR, 37.0\% of MLMR, $43.0 \%$ of HLMR and $16.0 \%$ of VHLRM. With regard to data collection, it was found that $59.0 \%$ of master's dissertations have $59.0 \%$ of LLMR, $21.0 \%$ of MLMR, $15.0 \%$ of HLMR and $5.0 \%$ of VHLRM. In relation to data analysis, verify that $25.0 \%$ of master's dissertations have $59.0 \%$ of LLMR, $66.0 \%$ of MLMR, $7.0 \%$ of HLMR and $2.0 \%$ of VHLRM. Finally, concerning results ascertain that master's dissertations have $19.0 \%$ of LLMR, $46.0 \%$ of MLMR, $31.0 \%$ of HLMR and $4.0 \%$ of VHLRM. 


\section{Discussion}

The results obtained were analysed according to the thirteen criteria compiled by Marques, Camacho and Alcantara (2015) from works carried out by several authors (ex: Heale and Forbes, 2013; Inayatullah, 2013; Yin, 2014).

The first six criteria analysed the dissertations in relation to their object of study, which proved to be the criterion with greatest methodological rigour. This result may be due to the fact that in all cases the phenomenon studied is investigated in its real context (criterion 1) and that there is a connection between the context and the phenomenon (criterion 2). The results are in line with those obtained by Marques, Camacho and Alcantara (2015), according to which there are certain phenomena that are not possible to study using other strategies, which emphasizes the importance of choosing the case study.

Regarding criterion 3, it was found that less than half of the dissertations explain the strategies used; these results can be explained by the authors' lack of knowledge about the importance of detailing this type of information, as stated by Alsharari and Al-Shboul (2019).

As far as the typology of the research question is concerned (criterion 4), the results were similar to those achieved by Yin (2014) in his works, and it was found that most of the questions asked are of the "how" type, which may be related to the lack of control that the researcher has over the studied phenomenon.

Regarding criterion five, the type of study carried out, the results obtained prove that the descriptive type was the most used, as concluded by Consoli et al. (2008), who developed a research work on the case study in the areas of management and marketing and concluded a high existence of research using the method for descriptive and exploratory purposes.

The explanation of the number of cases examined is important to provide evidence about their representativeness in relation to what is intended to be investigated (criterion 6). However, less than half of the dissertations are written with this criterion in mind, which suggests that there is no concern in justifying the choice of a single case or multiple cases. According to Yin (2014), the single case study is appropriate when it: (i) represents a theory that can be confirmed, challenged or expanded; (ii) characterizes an extreme or peculiar case; (iii) it is representative of the object of study; (iv) is revealing and previously inaccessible to investigation; and $(v)$ is longitudinal. The choice of multiple cases, in turn, is justified when there is a need to replicate studies that can predict similar results (Stewart, 2014). In recent years, this type of methodology has been common practice in the area of economic and business sciences, namely in terms of sustainable supply chain management. This can be corroborated by the study developed by Walker and Jones (2012), which used seven UK companies from different sectors (e.g., aerospace, retail, pharmaceutical, food and beverage) to identify the best practices for a better performance.

Criteria seven to nine focus on data collection, namely the sources of evidence, the possibility of triangulating the data and explaining the procedures. Thus, it was found that out of forty dissertations, the authors used more than one source of evidence (criterion 7), which allows the veracity of the information used in the analyses to be confirmed by means of data triangulation (criterion 8; Cesar, Antunes and Vidal, 2010). Heale and Forbes (2013) add that the use of multiple sources of evidence ensures that the case is investigated thoroughly and ensures the reliability of the data.

Criterion nine had as its main objective understanding if the way the data were collected is properly explained (e.g., how it was operationalized, where it occurred, what the steps were); it was found that this requirement was present in $99.0 \%$ of cases. According to Bhakar and Sikarwar (2014), detailed description of the procedures contributes significantly to increasing the methodological rigour of the investigations, since it allows their replication.

The analysis of psychometric indicators was assessed using criterion ten, as it is considered that their presence increases the validity and accuracy of the data evaluated (Hair et al., 2018). However, the authors note that from the 38 quantitative approach dissertations, only eight of them analyzed the psychometric properties of the instruments used. A possible explanation for this type of problem may be the lack of knowledge about the need 
to ensure the methodological rigour of the investigations that use a case study (Marques, Camacho and Alcantara, 2015).

Criterion eleven focused on explaining how the analyses were performed, as according to Alsharari and AlShboul (2019), the presence of this requirement helps to confer internal validity to the investigation. In our study, this criterion is present in $74.0 \%$ of the dissertations, which is a relevant point in qualitative research (Yin, 2014).

The methodological results, namely their comparison with the findings, was assessed using criterion twelve, which revealed that only thirty-five of the analysed dissertations evidence the contribution of the literature to corroborating the results obtained. These results suggest that the authors treat their studies in isolation and without considering what has already been done on the subject investigated. Similar conclusions were found by Cesar, Antunes and Vidal (2010), according to which, the researchers do not compare their results with previous studies because they did not consider it relevant to include this information in their work.

The last criterion analyses the existence of information regarding future lines of investigation in the scientific master's dissertations in management and marketing. In the analysis carried out, $81.0 \%$ of the cases contain this information. According to Inayatullah (2013), these results are expected, since the case studies address specific points that are analysed in depth and there are untested variables that could complement the results obtained with further investigation.

Finally, it was possible to ascertain that despite the identified gaps, more than half of the dissertations defended between 2015 and 2019 present high methodological rigour regarding the object of study and moderate regarding data analysis and results. The most critical aspects are related to the way the data are collected, namely the use of multiple sources of evidence in less than half of the cases, which makes triangulation of data impossible. Similar results were found by Gil, Licht and Oliva (2005) when analysing the case studies presented at a conference in the area of management.

\section{Conclusion}

The present work focuses on the use of the case study research method and analysis of the methodological rigour of the master's dissertations defended in the last five years in a private higher education institution, in the scientific area of management.

The following points show the results obtained:

1. There is a concern with understanding the phenomenon studied in its real context;

2. There is a connection between the phenomenon studied and the context in which it is inserted;

3. Despite its importance for validating methodological rigour, less than half of the dissertations explain the strategy used;

4. Most dissertations start their research questions with "How", which allows them to explore areas where research is scarce;

5. A small number of studies used the experimental type, so that the cause-effect relationship between the variables was presented in less than $10.0 \%$ of the cases;

6. There are few cases that state that the study is representative for the purpose of the investigation, most of which focused on a single case;

7. Many studies are based on only one source of evidence;

8. There is little triangulation of the data collected which does not allow confirming the accuracy of the information used in the analyses like it would be expected at this academic level;

9. With the exception of one case, all dissertations explained the procedures in detail;

10. The analysis of psychometric indicators was very low;

11. Explanation of the analyses carried out is present in most of the dissertations;

12. There is limited comparison with previous studies; and

13. There is a high number of cases where suggestions for future work are presented.

Consequently, we can conclude that, in general, the dissertations examined present a satisfactory level of methodological rigor in most of the dimensions considered. Thus, it is possible to state that the results obtained allow to answer the first research question. It was found that, with the exception of the data collection 
dimension which presents low values (59.0\%), $86.0 \%$ of the dissertations analysed show a level of methodological rigor ranging between moderate and very high in terms of the object of study, $81.0 \%$ in the results dimension and $75.0 \%$ in terms of data analysis (Marques, Camacho and Alcantara, 2015).

It was also verified that all the dissertations analysed seek to understand the phenomenon studied in its real context, which allows to answer affirmatively to the second research question. This point is crucial to guarantee the quality of the research, since the case study must represent the reality that one seeks to understand (Yin, 2017).

It is important to note that at the university under study the completion rate of dissertations (in relation to the number of master's students enrolled in the programs) has evolved from just over $20.0 \%$ in the pre-Bologna period, to around $50.0 \%$ in the period under analysis, or that is, in post-Bologna.

As limitations of the present study, it is important to note that a convenience sample was used, which has the disadvantage of not allowing inferences at the population level. In addition, the data were collected in a single educational institution, which includes, among others, scientific master's degrees $\left(2{ }^{\text {nd }} \mathrm{cycle}\right.$ ) in the management area. It should also be noted that the results found are valid for that period and for the dissertations analysed and cannot be generalized. Another limitation is related to the choice of evaluation criteria, as it appears that there is still little consensus among authors on the analysis of the case study as a research strategy or as a method of data collection (Yin, 2017).

Recognizing that this study does not allow conclusions to be drawn or definitive answers to be provided, we believe that it may contribute to this reflection around methodological rigour in case studies. The high agreement found between the results presented here and many other studies (e.g., Cesar, Antunes and Vidal, 2010; Yin, 2014; Marques, Camacho and Alcantara, 2015) suggests that the general lines of this study are valid.

Taking this into account, it is considered pertinent to extend the analysis to all dissertations anchored in the case study ( $n=177$ ) that were defended between 2009 and 2019, in order to understand the evolution of their methodological rigour. A similar analysis is also suggested for the remaining 265 dissertations defended at that educational institution to compare the methodological rigour of the works presented, according to the methodology used.

\section{References}

Alsharari, N. and Al-Shboul, M., 2019. Evaluating qualitative research in management accounting using the criteria of "convincingness". Pacific Accounting Review, 31(1), pp.43-62. https://doi.org/10.1108/IJPSM-10-2018-0217.

Ajayi, V. O., 2017. Primary sources of data and secondary sources of data. PhD. Benue State University

Alam, M. K., 2020. A systematic qualitative case study: Questions, data collection, NVivo analysis and saturation. Qualitative Research in Organizations and Management: An International Journal, 15, pp.1-31. https://doi.org/10.1108/QROM-09-2019-1825.

Barratt, M., Choi, T. and Li, M., 2011. Qualitative case studies in operations management: Trends, research outcomes, and future research implications. Journal of Operations Management, 29(4), pp.329-342. https://doi.org/10.1016/j.jom.2010.06.002.

Bhakar, S. and Sikarwar, T., 2014. Handbook for Writing Research Paper. Delhi: Bharti Publications.

Bogdan, R. and Biklen, S., 2013. Qualitative research in education: an introduction to theory and methods. Porto: Porto Editora.

Caldwell, D., 2019. Alexander L. George: A Pioneer in Political and Social Sciences. New York: Springer.

Cesar, A., Antunes, M. and Vidal, P., 2010. Case study method in accounting research: a comparison of its methodological rigor in national and international publications. Revista de Informação Contábil [Accounting Information Magazine], 4(4), pp.42-64. https://doi.org/10.1590/1808-057×201500280.

Consoli, M., Musetti, M., Scare, R. and Fratantonio, W., 2008. A discussion on the use of case studies as a research method in managerial sciences. Rio de Janeiro: ANPAD.

Creswell, J. W., 2013. Qualitative inquiry and research design: Choosing among five approaches. Thousand Oaks, CA: Sage.

Eisenhardt, K. M. and Graebner, M. E., 2007. Theory building from cases: Opportunities and challenges. Academy Of Management Journal, 50(1), pp.25-32. https://doi.org/10.5465/amj.2007.24160888.

Flynn, B., 2008. Having it all: Rigor versus relevance in supply chain management research. Journal of Supply Chain Management, 44(2), pp.63-67. https://doi.org/10.1111/j.1745-493X.2008.00056.X.

Gehman, J., Glaser, V. L., Eisenhardt, K. M., Gioia, D., Langley, A. and Corley, K. G., 2018. Finding theory-method fit: A comparison of three qualitative approaches to theory building. Journal of Management Inquiry, 27(3), pp.284-300. https://doi.org/10.1177/1056492617706029. 
Gephart, R. P. and Saylors, R., 2020. Qualitative Designs and Methodologies for Business, Management, and Organizational Research. In: Oxford Research Encyclopedia of Business and Management. [online]. Available at <https://oxfordre.com/business/view/10.1093/acrefore/ 9780190224851.001.0001/acrefore-9780190224851-e230> [Accessed 27 December 2020].

Gil, A., Licht, R. and Oliva, E., 2005. Case study method in business administration research. Revista de Administração e Contabilidade da Unissinos [Unisinos Magazine of Administration and Accounting], 2(1), pp.47-56.

Godoy, A., 2006. Qualitative case study. In: C. Godoi, R. Melo and A. Silva, orgs. 2006. Qualitative research in organizational studies: paradigms, strategies and methods. São Paulo: Saraiva. pp.115-146.

Goffin, K., Åhlström, P., Bianchi, M. and Richtnér, A., 2019. Perspective: State-of-the-art: The quality of case study research in innovation management. Journal of Product Innovation Management, 36(5), pp.586-615. https://doi.org/10.1111/jpim.12492.

Gustafsson, J., 2017. Single case studies vs. multiple case studies: A comparative study [pdf]. Available at <https://www.diva-portal.org/smash/get/diva2:1064378/FULLTEXT01.pdf> [Accessed 28 December 2020].

Hair, J., Black, W., Babin, B., Anderson, R. and Tatham, R., 2018. Multivariate Data Analysis. Upper Saddle River, NJ: Pearson Prentice Hall.

Harley, B. and Cornelissen, J., 2019. Reframing Rigor as Reasoning: Challenging Technocratic Conceptions of Rigor in Management Research. In: T. B. Zilber, J. M. Amis and J. Mair, eds. 2019. The Production of Managerial Knowledge and Organizational Theory: New Approaches to Writing, Producing and Consuming Theory. Bingley: Emerald Group Publishing Limited, pp.59-76.

Harrison, H., Birks, M., Franklin, R. and Mills, J., 2017. Case study research: Foundations and methodological orientations. FQS: Forum Qualitative Social Research, 18(1), pp.1-17.

Harrison, R. L., Reilly, T. M. and Creswell, J. W., 2020. Methodological Rigor in Mixed Methods: An Application in Management Studies. Journal of Mixed Methods Research, 14(4), pp.473-495. https://doi.org/10.1177/1558689819900585.

Heale, R. and Forbes, D., 2013. Understanding triangulation in research. Evidence Based Nursing, 16(4), 98. http://dx.doi.org/10.1136/eb-2013-101494.

Heale, R. and Twycross, A., 2015. Validity and reliability in quantitative research. Evidence Based Nursing, 18(3), pp.66-67. http://dx.doi.org/10.1136/eb-2015-102129.

Holmlund, M., Witell, L. and Gustafsson, A., 2020. Getting your qualitative service research published. Journal of Services Marketing, 34(1), pp.111-116. https://doi.org/10.1108/JSM-11-2019-0444.

Hoorani, B. H., Nair, L. B. and Gibbert, M., 2019. Designing for impact: The effect of rigor and case study design on citations of qualitative case studies in management. Scientometrics, 121(1), pp.285-306. https://doi.org/10.1007/s11192-01903178-w.

Inayatullah, S. (2013) Futures studies: Theories and methods [online]. Available at <https://www.researchgate.net/publication/281595208_Futures_Studies_Theories_and_Methods> [Accessed 20 December 2020].

Johnson, J. L., Adkins, D. and Chauvin, S., 2020. A review of the quality indicators of rigor in qualitative research. American Journal of Pharmaceutical Education, 84(1), pp.138-146. https://doi.org/10.5688/ajpe7120.

Ketchen Jr, D. , Craighead, C. and Cheng, L., 2018. Achieving research design excellence through the pursuit of perfection: Toward strong theoretical calibration. Journal of Supply Chain Management, 54(1), pp.16-22. https://doi.org/10.1111/jscm.12156.

Labani, S., Wadhwa, S. and Asthana, W., 2017. Basic Approach to Data Analysis and Writing of Results and Discussion Sections. Journal of Medical Sciences, 3(1), pp.6-15. https://doi.org/10.4103/ mamcjms.mamcjms_50_16.

Marques, K., Camacho, R. and Alcantara, C., 2015. Assessment of the Methodological Rigor of Case Studies in the Field of Management Accounting Published in Journals in Brazil. Revista de Contabilidade \& Finanças [Accounting \& Finance Magazine], 26(67), pp.27-42. https://doi.org/10.1590/1808-057x201500280.

Miles, M. B., Huberman, A. M. and Saldana, J., 2014. Qualitative data analysis: a methods sourcebook. Thousand Oaks, CA: Sage.

Molina-Azorin, J. F. and Fetters, M. D., 2020. In This Issue: Mixed Methods Case Study, Fractal Heuristics and Integration, Methodological Rigor and Quality, Q Methodology, and Game Heuristics in Journal of Mixed Methods Research. Journal of Mixed Methods Research, 14(4), pp. 427-429. https://doi.org/10.1177/1558689820956400.

Myers, M. D., 2019. Qualitative Research in Business and Management. Thousand Oaks, CA: Sage.

Piekkari, R. and Welch, C., 2011. Pluralism in international business and international management research: making the case. In: R. Piekkari and C. Welch, eds. 2011., Rethinking the case study in international business and management research. Cheltenham, UK: Edward Elgar, pp.3-23.

Rahman, M. S., 2017. The advantages and disadvantages of using qualitative and quantitative approaches and methods in language "testing and assessment" research: A literature review. Journal of Education and Learning, 6(1), pp.102-112. http://dx.doi.org/10.5539/jel.v6n1p102.

Rashid, Y., Rashid, A., Warraich, M. A., Sabir, S. S. and Waseem, A., 2019. Case Study Method: A Step-by-Step Guide for Business Researchers. International Journal of Qualitative Methods, 18, pp.1-13. https://doi.org/10.1177/1609406919862424.

Shufutinsky, A., 2020. Employing use of self for transparency, rigor, trustworthiness, and credibility in qualitative organizational research methods. OD Practitioner, 52(1), pp.50-58. 
Stewart, A., 2014. Case study. In: J. Mills and M. Birks, eds. 2014. Qualitative methodology: A practical guide Thousand Oaks, CA: Sage, pp.145-159.

Takahashi, A. R. W. and Araujo, L., 2019. Case study research: opening up research opportunities. RAUSP Management Journal, 55(1), pp.100-111. https://doi.org/10.1108/RAUSP-05-2019-0109.

Thomas, G., 2011. A typology for the case study in social science following a review of definition, discourse, and structure. Qualitative Inquiry, 17(6), pp.511-521. https://doi.org/10. 1177/1077800411409884.

Verleye, K., 2019. Designing, writing-up and reviewing case study research: an equifinality perspective. Journal of Service Management, 30(5), pp.549-576. https://doi.org/10.1108/JOSM-08-2019-0257.

Walker, C. and Baxter, J., 2019. Method Sequence and Dominance in Mixed Methods Research: A Case Study of the Social Acceptance of Wind Energy Literature. International Journal of Qualitative Methods, 18, pp.1-14. https://doi.org/10.1177/1609406919834379.

Walker, H. and Jones, N., 2012. Sustainable supply chain management across the UK private sector. Supply Chain Management: An International Journal, 17(1), pp.15-28. https://doi.org/10.1108/13598541211212177

Yazan, B., 2015. Three Approaches to Case Study Methods in Education: Yin, Merriam, and Stake. The Qualitative Report, 20(2), pp.134-152. https://nsuworks.nova.edu/tqr/vol20/iss2/12

Yin, R. (2010) Case study: planning and methods. Porto Alegre: Bookman.

Yin, R. (2013) Validity and generalization in future case study evaluations. Evaluation, 19(3), pp.321-332. https://doi.org/10.1177/1356389013497081.

Yin, R. (2014) Case Study Research: Design and Methods. Thousand Oaks, CA: Sage.

Yin, R. (2017) Case Study Research and Applications: Design and Methods. Thousand Oaks, CA: Sage. 